\title{
The Construction of Teaching System of Intercultural Communication Course for Japanese Major
}

\author{
Yan Qing \\ School of Foreign Studies, Xi'an University, 710065
}

Keywords: Japanese major; Intercultural communication; Course; Teaching system

\begin{abstract}
In the context of global economic integration, the exchanges between countries are becoming increasingly close, and good communication needs to be based on well fundamentals of language. China and Japan have had a long history of communication, but there are still many problems in cross-cultural communication between China and Japan. Throughout the domestic language colleges, the construction of the teaching system of intercultural communication courses for Japanese major is still in the exploratory stage. Based on the existing theoretical research results, this paper analyzes the shortcomings of domestic institutions in the education of Japanese intercultural communication. Secondly, the author analyzes the current situation of cross-cultural communicative education of Japanese major as well as the achievements in the intercultural communication of other language majors, and thus provides reasonable recommendations to the construction of teaching system of intercultural communication course for Japanese major.

The cross-cultural communication issues were concerned by international field in 1960s. Media, mass communication, sociology, anthropology and other schools particularly pay attention to the cross-cultural issues. Since the 1980s, China has gradually started to explore the issue of intercultural communication. Until the end of the 20th century and the early 21 st century, the training focus on students of foreign language majors in colleges and universities has also been transformed into cross-cultural communicative ability. The significance of cultivating intercultural communicative ability, on one hand, lies in the promotion of the comprehensive strength of foreign language talents; and on the one hand, it is conducive to international cooperation and exchanges. With the development of the times, Internet communication and frequent exchanges between countries around the world, foreign language talents not only need to master the ability of translation and expression of language, but also need to master the actual ability of international communication. Only when the level of cross-cultural communication of foreign language talents rises to a certain extent, can they play a strong promoting role in national diplomatic relations. In the research interests of cross-cultural communication, China has studied the field from multiple perspectives and multi-facets, and the research results have been endless. First of all, Chinese scholars have performed in-depth theoretical research in the field and have also published a large number of research results. Secondly, the syllabus of the universities also introduces the cultivation of intercultural communicative competence and gradually increases its proportion. Japan, as a neighbor of China, both have a deep origin in culture and international life, but also have many conflicts. At present, the domestic study of intercultural communication in Japanese major is still in the stage of exploration. Therefore, it is imperative to strengthen the study of this field and promote the good communication between the two countries. For colleges and universities, foreign language majors should construct a reasonable and effective teaching system of intercultural communication courses for Japanese major to continuously provide high-level Japanese talents for the society to and constantly output the research results of intercultural communication in Japanese. The following is a brief analysis of Chinese and Japanese cross-cultural studies:
\end{abstract}

\section{Chinese and Japanese Cross-Cultural Studies}

\section{Revelation of the Deficiency of Japanese Language Teaching Mode}

The lack of Japanese language teaching mode is an important factor restricting the intercultural communication of Japanese professionals. Students in Japanese major are difficult to master the actual communicative ability under the traditional teaching mode of listening, speaking, reading, 
and writing. Fundamentally speaking, it is the problem of learning environment. The context is essential for language learning. Without appropriate context, students cannot understand the meaning of the language and will not know how to apply it. Therefore, we should introduce the Japanese cultural environment in the Japanese language teaching. There are a lot of articles about this kind of research in China, which are mainly divided into the following categories: (1) to explain how the culture causes interference on Japanese learning by analyzing the specific meaning of the word in the Japanese culture, directional thinking, body language, etc.; (2) to study how the common learning principle influences the language ability and intercultural ability of foreign language learners; (3) to study the culture of Japan in depth and explore its cultural characteristics so as to provide theoretical basis and practical guidance for Japanese learning.

\section{Revelation of Cultural Differences between China and Japan and the Caused Communicative Barriers}

After introducing Japanese culture in college Japanese education, we should compare Japanese culture with Chinese culture on the basis of its in-depth study to find out the difference and the conflict point between them, and analyze these differences and contradictions which may lead to barriers in cross-cultural communication. Cross-cultural communication is based on language, non-language and other aspects of the basis of all factors, which should be a comprehensive study. At present, there are few research results in this field, of which the contents are similar. Published papers mainly analyze cultural differences between China and Japan and the caused communicative barriers from the perspective of thinking habits, living habits, etc.

\section{Revelation of the Basic Principles of Intercultural Communication between China and Japan}

The study of Japanese culture and analysis of its differences with Chinese culture in Chinese and Japanese cross-cultural communication can make people fully respect each other's culture and follow certain basic principles in communication. The main research directions of domestic related research results are as follows: from the current communicative situation between Japan and China, the main ways and the direction of strengthening cross-cultural communication between the two countries are emphasized, the importance of combination of explicit communication and implicit communication is stressed, and the specific values and ways of thinking are clarified to be the main barrier to cross-cultural communication between the two countries.

\section{Teaching Practice of Cross-Cultural Course in Foreign Language Majors}

In view of the current situation of cross-cultural communication between China and Japan, a number of domestic research institutions and units explore a lot of theoretical research and teaching practice. This paper, taking the universities that are relatively successful in teaching practice of Chinese and Japanese cross-cultural course as an example, illustrates the existing problems in the current educational practice and puts forward suggestions for improvement.

First of all, we would like to take three language universities, viz. the Shanghai International Studies University, Guangdong University of Foreign Studies and Dalian University of Foreign Language as an example. There are obvious differences in the arrangement of undergraduate language courses and graduate language courses. The Japanese major of Shanghai International Studies University has opened related ordinary courses of Japanese language learning, while the number of courses related to cross-cultural communication is zero. Similarly, Dalian University of Foreign Language has carried out a number of courses to cultivate students' Japanese translation ability and Japanese language combined with other languages, such as Japanese and English bilingual classes, Japanese and Korean bilingual classes, advanced translation classes and so on. However, there is no course of any intercultural communication related to Japanese. Guangdong University of Foreign Studies is exactly the same as the other two universities.

Secondly, the other language majors of these three universities have been compared. It can be 
found that in the cross-cultural communication courses of the other language majors, these three universities have established a better course system. Shanghai International Studies University has established a systematic cross-cultural communication courses and English cross-cultural research center in English major. Guangdong University of Foreign Studies has established a targeted cross-cultural communication course in French, and the study of the course has lasted for more than ten years. The two universities have achieved significant research and practical experience in the field of cross-cultural communication in English and French, respectively.

Although the three universities mentioned above do not have systematic cross-cultural communicative teaching system in Japanese major, their achievements in other language majors can provide a good reference. In the following section, the author introduces the method of establishing a reasonable intercultural communication teaching system and the intercultural communicative ability of students in the intercultural communication courses offered by the Cross-cultural Research Center of Shanghai International Studies University and other foreign language majors of Guangdong University of Foreign Studies.

Firstly, the Cross-cultural Research Center of Shanghai International Studies University has been targeted to set up the intercultural communicative ability and cross-cultural communicative foundation for the design of compulsory course for postgraduate students, including five theoretical courses: history and current situation, important reading of cross-cultural communication and mass communication, cross-cultural research methods, cross-culture and indigenous core culture, value and identity research, which aim at cultivating students' ability to use theoretical basis to think about research. For the design of graduate elective courses, the research center has opened four courses, including culture and translation, cross-cultural education and training, cross-cultural business communication, cross-cultural theory and practice, which aim at cultivating students' practical ability to intercultural communication. It can be found that the center's main framework of the training on graduate students is mainly based on theoretical study, with guiding practice as the assistance.

Secondly, Guangdong University of Foreign Studies has opened cross-cultural communication courses which are mainly for undergraduate students. The feature is that the early learning is mainly related to daily life connected with cross-cultural communication courses, and the later learning is mainly the course related to business practice.

It can be seen that the universities set up different courses and teaching systems for the students at various stages. For undergraduates, the learning ability is slightly worse, so the arrangement of the course is mainly from easy to difficult. The overall theory of the course is weaker, and the basic knowledge is mainly studied in the early stage, and the training of practical experience is emphasized in the later period. For graduate students, the ability of acceptance and thinking are strong. Therefore, the course setting is mainly used in combination with the theory and practice. Compulsory courses are mainly theoretical knowledge, thus laying a solid foundation. Elective courses are mainly related to practice, so as to better combine both and complement each other.

\section{The Construction of Japanese Intercultural Communication Teaching System}

In order to further speed up and improve the construction of the teaching system of intercultural communication in Japanese major, the colleges and universities can make efforts from the following aspects.

First of all, universities and colleges should improve the direction of cross-cultural communication of Japanese major and business-related aspects of the training program and develop a reasonable course to systematically cultivate the students in the direction.

Next, reasonable course should include the following parts. 1. Basic course arrangement of Japanese-related orientation at the early stage of the entrance. We should strengthen the basic knowledge of Japanese language students in listening, speaking, reading, writing and translating, and mainly arrange courses for Japanese language classes. 2. Increasing the number of Japanese culture related courses after studying for a while. Through the early learning and accumulation, students have a more comprehensive grasp in Japanese language and basic situation and establish a 
certain Japanese foundation. At this moment, the introduction of Japanese culture, on one hand, can play a solid role in the language students mastering. On the other hand, it is conducive to further understand Japanese, to experience the Japanese values and ways of thinking with empathy, thus eliminating some inherent prejudice against Japanese and removing cross-cultural communicative barriers. Japanese culture related courses are including Japanese history, Japanese film appreciation, Japanese business negotiations, Japanese traditional customs, Japanese writing characteristics, Japanese economic development, etc. Related courses should be comprehensive coverage of the economy, literature, science and technology and other fields. 3. The combination of learning methods of theoretical learning and practical application. No matter what language, the application is very important. Only by using the knowledge we have, can we truly master the essence of language. 4. Different training methods are adopted for different students. Undergraduates are different from graduate students. Undergraduates may have no basic knowledge of Japanese culture, so their teaching focus should first be on the basic knowledge teaching. When they accumulate the basic knowledge to a certain extent, they could accept practical application training. For graduate students, they themselves have certain knowledge of Japanese reserves, so after enrolling to university, they should first focus on the transfer of theoretical knowledge which mainly trains their ability to use the theory to think and study. Secondly, on this basis, the practical application of supporting education should be performed.

Finally, Japanese teachers' teaching methods need to be improved. Japanese teachers should abandon the education way of endorsement, and guide students learn Japanese and practice with the right way. In addition, Japanese teachers should actively participate in Japanese related research work of cross-cultural communication, and have more comprehensive and in-depth understanding on the Japanese culture. Japanese teachers should find out the root causes of cross-cultural communicative barriers between China and Japan, and establish a sound and perfect teaching system, so as to better cultivate high-quality diplomatic talents for the motherland and promote the development of the foreign affairs of the motherland.

\section{Conclusion}

Based on the current research achievements of Japanese intercultural communication in our country, this paper analyzes the shortcomings of the current teaching model in Japanese language, and demonstrates that the cultural differences between China and Japan are the main reasons for the obstacle of communications between the two countries. In order to better carry out Chinese and Japanese cross-cultural communication, the colleges and universities must make full use of the current theoretical research results, perform the reform of teaching course arrangements, and increase the Japanese culture-related course so that because of learning of Japanese culture, students in Japanese major can deepen the understanding of Japanese and perform better communication practices. In this paper, we compare the course of Japanese related majors in representative language colleges and put forward reasonable suggestions to promote the construction of a more reasonable Japanese intercultural communication teaching system and promote the construction of teaching system of the international intercultural courses of Japanese major.

\section{Reference}

[1] G.F. Liu, C.H. Wang, L.P. Jia: A case study on the professional design of business English majors - A case study of cross-cultural business communication. Vocational and Technical Education, Vol. 14 (2012), p. 48. (In Chinese)

[2] H. Cui: Research on the construction strategy of public oral English teaching system based on ESP. Journal of Nanjing University of Aeronautics \& Astronautics (Social Sciences), Vol. 01 (2011), p. 74. (In Chinese)

[3] Content of Issue 1-6, 2011, Journal of Harbin Vocational and Technical College. Journal of Harbin Vocational and Technical College, Vol. 06 (2011), p. 124. (In Chinese)

[4] M.Q. Li: The innovation of foreign language teaching and the cultivation of intercultural 
communicative competence in CDIO educational idea. Journal of Beijing University of Chemical Technology (Social Science Edition), Vol. 03 (2015), p. 71. (In Chinese)

[5] H.Y. Hou, R.Z. Wu, J.H. Feng: The construction of talent cultivation model of foreign tour guides in Baoding City from the perspective of cross - culture. Science and Education, Vol. 04 (2016), p. 170. (In Chinese)

[6] Y. Liu: A study on the construction of Japanese language curriculum system and the reform of teaching reform for postgraduates - Taking China University of Mining and Technology as an example. Journal of Lanzhou Education College, Vol. 10 (2016), p. 130. (In Chinese)

[7] M.X. Peng: The present situation and countermeasure of translation course in Japanese teaching - Constructing the curriculum system of cultivating practical translation talents. Journal of Jilin University of Foreign Languages, Vol. 01 (2009), p. 86. (In Chinese)

[8] Z.J. Zou: Construction and practice of the teaching system of tourism product design from the perspective of regional culture - Taking the specialty of product design of Guilin University of Technology as an example. Industrial Design, Vol. 03 (2017), p. 72. (In Chinese)

[9] Z. Hao: The curriculum system and teaching mode construction of business Japanese major in higher vocational education. Journal of Bohai University (Philosophy and Social Sciences), Vol. 03 (2013), p. 150. (In Chinese)

[10] L. Wang: Reflections on Japanese teaching and improving students' cultural quality. Journal of Southwest University for Nationalities (Humanities and Social Sciences), Vol. S1 (2010), p. 84. (In Chinese)

[11] H. Wei and M. Wei: Research on the indigenous cultural teaching of intercultural communication course for English majors in local applied undergraduate universities. Chinese Journal of Foreign Language Education, Vol. 02 (2015), p. 79. (In Chinese)

[12] M.X. Peng: The present situation and countermeasure of translation course in Japanese teaching - Constructing the curriculum system of cultivating practical translation talents. Journal of Jilin University of Foreign Languages, Vol. 01 (2009), p. 86. (In Chinese)

[13]X. Chen: The cultivation of new Japanese talents and the reform of curriculum design - From the perspective of intercultural communicative competence and cultural cognition. Chinese Journal of Foreign Language Education, Vol. 11 (2013), p. 129. (In Chinese) 